\title{
Experience with Three Brescia-Cimino Shunts
}

\author{
R. MCMILLAN,* M.B., CH.B.; D. B. EVANS,* M.B., B.CH., M.R.C.P.
}

\begin{abstract}
Cummary : Brescia-Cimino shunts inserted to facilitate intermittent dialysis may markedly increase the circulatory load on the heart. Three patients in whom there was evidence of overload are described. Thorough investigation of the cardiac output should be made in patients with fistulae of this kind, which should be closed as soon as practicable after transplantation.
\end{abstract}

\section{Introduction}

Since the description of the surgically created arteriovenous fistula by Brescia et al. (1966) for patients in end-stage renal failure on intermittent haemodialysis the technique has become increasingly popular. Other writers have described their experience with the fistula and also their operative technique (Hanson et al., 1967 ; Patel et al., 1968). The same procedure has been used to provide adequate veins for patients requiring multiple transfusions, for example, in aplastic anaemia (Anderson et al., 1967).

A number of authors have attempted to assess the haemodynamic effects of such a fistula, with varying results. Klinkmann et al. (1967) studied four patients before and after the construction of such a fistula. Five months after construction of the fistula they found that: (1) right heart pressures were raised, (2) there was a distinct rise in cardiac output, and (3) in one of these patients there were electrocardiographic and phonocardiographic changes of right heart strain. These authors felt that a small arteriovenous anastomosis lessened the strain on the right side of the heart and that adequate control of systemic hypertension with careful control of hydration was also important. Ackman et al. (1967) described a hypertensive male patient whose cardiac output rose from 9 to 12 litres/minute when the fistula was open. This increased cardiac output was corrected by reducing the size of the arteriovenous anastomosis. Though all these authors had studied the cardiac output in their patients with fistulae, it is not clear whether this was done after exercise or at rest only. Hanson et al. (1967), however, do state that they found no instance of cardiac embarrassment in any of their 15 patients with fistulae.

* Addenbrooke's Hospital, Cambridge.
Verberckmoes et al. (1967), in describing their experience in this field, mention two patients who died suddenly while otherwise apparently well, but do not give any explanation for their deaths. We know of one other sudden death, that of a 20year-old man who was being haemodialysed by means of a Brescia-Cimino shunt.

In Cambridge, haemodialysis is undertaken only as a preoperative and postoperative maintenance for patients on the renal transplant programme. We have not to date constructed a fistula of this type in any of our patients, as the average time on dialysis is six weeks (Calne et al., 1968). However, of 50 patients treated here, three have come from other centres with a functioning Brescia-Cimino fistula. Of these, two had radiocephalic fistulae with a side-to-side anastomosis, and were created electively for dialysis. The third patient, when conventional Scribner shunt sites had all been used, came to us with a side-to-side anastomosis utilizing his left ulnar artery and vein.

This report describes our experience with these three patients.

\section{Case 1}

A 34-year-old man with end-stage renal failure due to chronic glomerulonephritis was admitted to Cambridge with a functioning Scribner shunt in his left leg and a radiocephalic anastomosis at his left wrist. His general condition on admission was good and he had no respiratory symptoms. On examination his blood pressure was $120 / 70 \mathrm{~mm}$. $\mathrm{Hg}$, jugular venous pressure was not raised, no abnormal heart sounds were heard, but there was a soft apical systolic murmur.

On the day after admission a renal transplant was performed, the donor of the kidney having died of head injuries sustained in an accident. On the ninth postoperative day the patient became febrile with a pseudomonas septicaemia. The same organisms had been cultured from the donor's sputum. The septicaemia responded to antibiotic therapy and satisfactory transplant function was attained. During this time the leg shunt clotted and was removed. The septicaemia recurred, however, on the 32 nd day. On this occasion therapy was unsuccessful and there was a subsequent deterioration in transplant function. A combination of sepsis, rejection, and marrow depression proved insuperable and he died on his 83 rd postoperative day. At necropsy the patient weighed $56 \mathrm{~kg}$. and his heart $360 \mathrm{~g}$. There was no evidence of endocarditis.

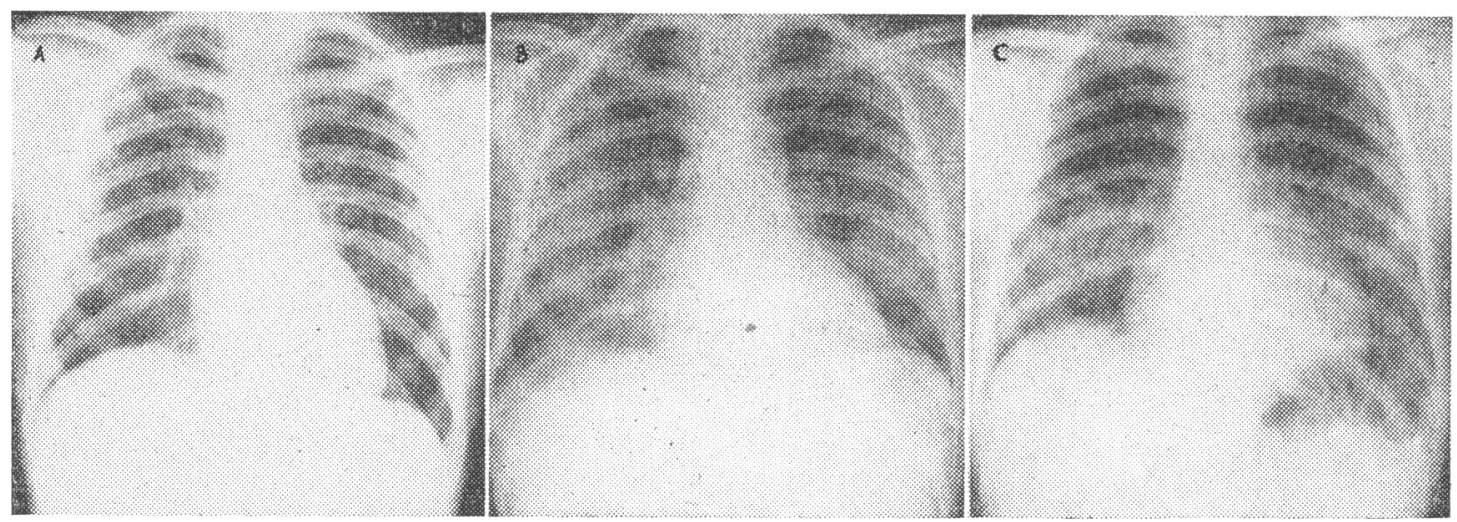

Figs. 1A, 1B, and 1C.-Case 1. Chest radiographs. 
Figs. 1a, 1b, and 1c show the progressive enlargement of the heart and the prominent pulmonary vessels. E.C.G.s at the time were within normal limits.

\section{Case 2}

The patient was a 39 -year-old man with malignant hypertension and chronic renal failure due to chronic glomerulonephritis. On admission he had no respiratory symptoms, his blood pressure was $180 / 120$ despite $2 \mathrm{~g}$. of methyldopa daily, a soft apical systolic murmur and a fourth heart sound were present, but the jugular venous pressure was not raised. A radiocephalic fistula was present at his left wrist with good proximal and distal flow. He was satisfactorily haemodialysed once before receiving a live donor renal transplant which functioned well immediately.

On the third postoperative day the jugular venous pressure was raised $+1 \mathrm{~cm}$; the second pulmonary heart sound was noted to be widely split and fine crepitations were present at both lung bases. Despite treatment his condition deteriorated and he developed pleuritic pain on the right side which was thought to be due to a pulmonary infarct. Three days later there was clinical improvement and the chest film showed clearing at both bases but apparent dilatation of the right pulmonary artery. One week later, even with intensive therapy, he was in severe left ventricular failure with blood pressures of the order of 220-230/130-140. The E.C.G. at this time showed tachycardia and severe left ventricular strain. On the 19th postoperative day a diagnosis of transplant rejection was made; this was treated in the usual way (Calne et al., 1968). On the 21st day it was felt that his clinical condition, renal function, and uncontrollable blood pressure could best be treated by immediate dialysis.

A combination of poor blood flow from the Brescia-Cimino shunt and a burst membrane on the Kiil dialyser meant that the dialysis had to be abandoned. Subsequently a standard Scribner shunt was inserted into his left arm proximal to the arteriovenous fistula, which was not closed. Dialysis began immediately and was continued for 12 hours, when he died.

At necropsy the patient weighed $52 \mathrm{~kg}$. and the heart $495 \mathrm{~g}$. There was hypertrophy of the walls of both ventricles and evidence of severe myocardial ischaemia with multiple infarcts of the right lung.

Figs. $2 \mathrm{a}, 2 \mathrm{~b}$, and $2 \mathrm{c}$ show $x$-ray appearances $(a)$ before and $(b)$ after fistula formation and $(c)$ shortly before the patient's death. These demonstrate the progressive increase in heart size and prominence of the pulmonary artery. The E.C.G. also shows increasing left ventricular strain and hypertrophy (Fig. 3).

\section{Case 3}

A 41-year-old man with chronic renal failure due to chronic glomerulonephritis was admitted with an arteriovenous fistula in his left wrist using his ulnar artery and a superficial vein, which had been created for lack of conventional shunt sites. On admission his general condition was good, jugular venous pressure was not raised, and B.P. was $170 / 120$. There was a loud pulmonary second

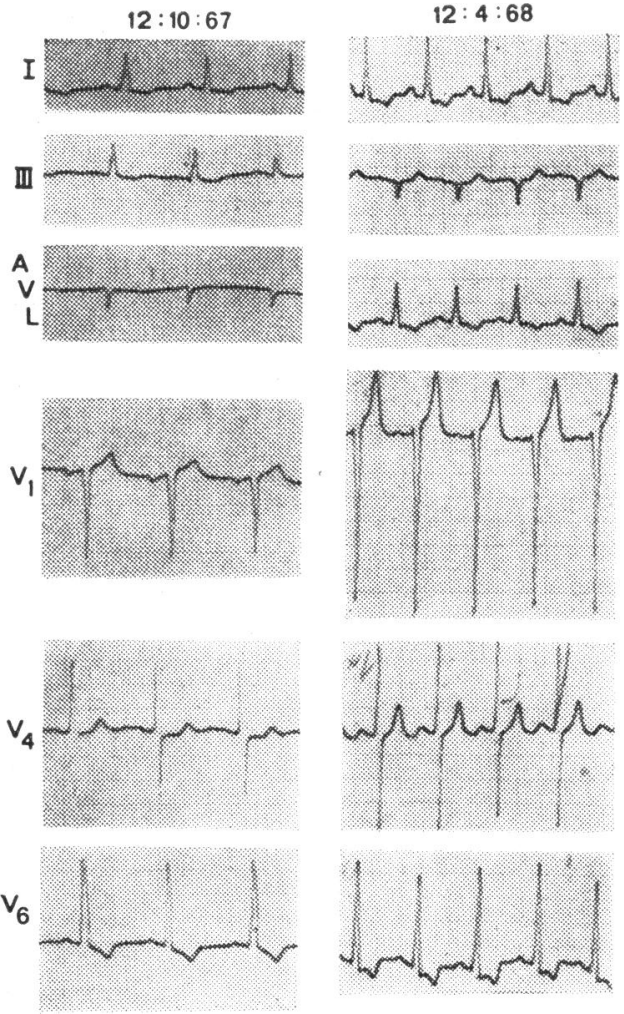

FIG. 3.-Case 2. E.C.G.

sound but the chest was clinically clear. Fairly satisfactory dialyses were achieved with the fistula, but the absence of a significant peripheral flow made it necessary to use the opposite arm for venous returns on several occasions. After cadaveric renal transplantation diuresis occurred on the 16th day, since when his progress had been satisfactory. Subsequently, however, in spite of good transplant function, progressive exertional dyspnoea was noted. Accordingly his cardiac output was measured, using the Cardiogreen dye dilution technique, with the following results:

\begin{tabular}{|c|c|c|c|}
\hline \multicolumn{2}{|l|}{ Patient } & \multirow{2}{*}{$\begin{array}{l}\text { Shunt } \\
\begin{array}{l}\text { Closed } \\
\text { Open }\end{array} \\
\end{array}$} & \multirow{2}{*}{$\begin{array}{l}\text { Cardiac Output } \\
5.5 \text { litres/min. } \\
5.8 \text { litres/min. }\end{array}$} \\
\hline $\begin{array}{l}\text { Resting supine } \ldots \\
\text { Resting supine } \quad . .\end{array}$ & 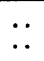 & & \\
\hline $\begin{array}{l}\text { After exercise sitting } \\
\text { After exercise sitting }\end{array}$ & $\because$ & $\begin{array}{l}\text { Closed } \\
\text { Open }\end{array}$ & $\begin{array}{l}7 \cdot 2 \text { litres } / \mathrm{min} . \\
10 \cdot 2 \text { litres } / \mathrm{min} \text {. }\end{array}$ \\
\hline
\end{tabular}

As the exercise load was the same in each case it was felt that these figures indicated a significant extra load on the patient's heart and the fistula was subsequently closed surgically.
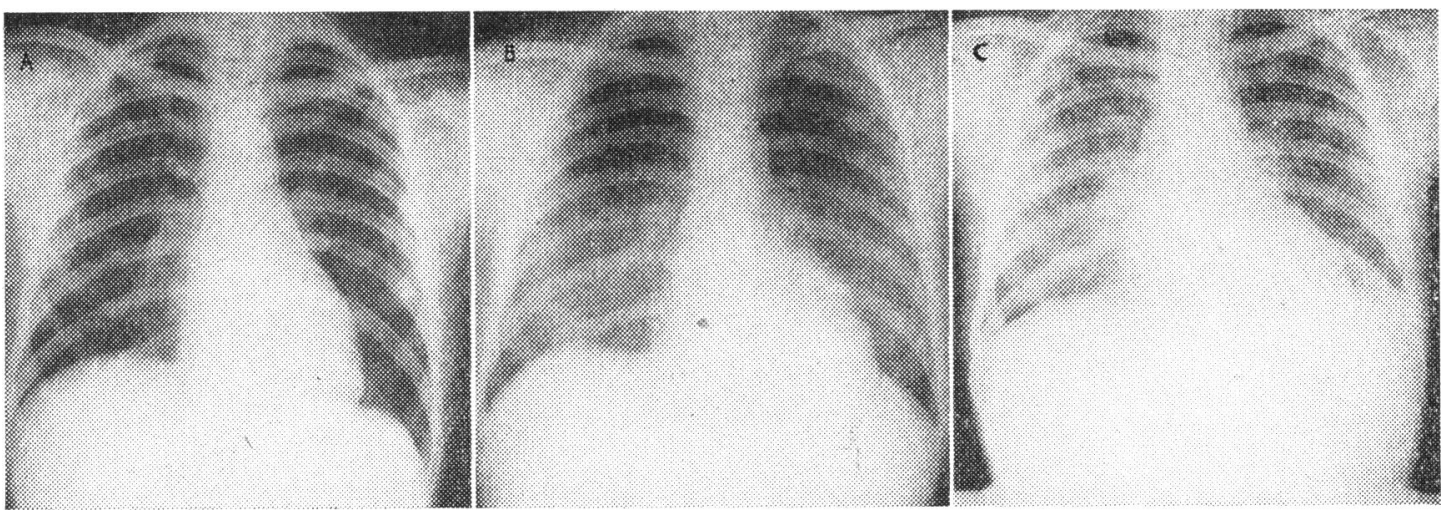

FIGs. 2A, 2B, and 2C.-Case 2. Chest radiographs. 
Fig. 4 did not show significant increase in heart size from earlier examinations. E.C.G.s at the time showed no gross changes.

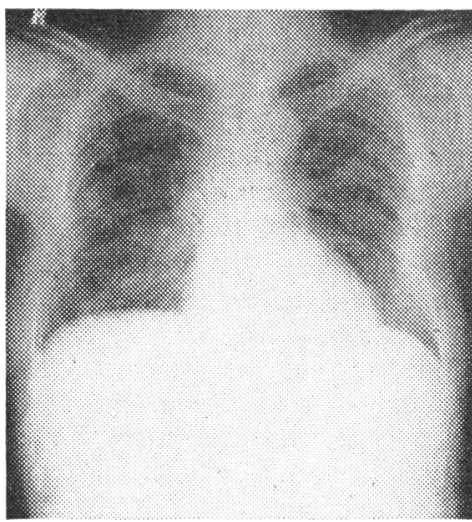

FIg. 4.-Case 3. Chest radiograph.

\section{Discussion}

Our experience in three cases of arteriovenous fistulae is described. We have not to date been impressed with the flow rates obtained during dialysis, nor do we consider setting up dialysis a convenient procedure, as compared with our experience with conventional Scribner shunts. The fistula in Case 3 was the only one which in our hands yielded satisfactory dialyses. In Cases 1 and 3 there was no significant distal flow to provide a safety valve as described by Klinkmann et al. (1967).

We feel in retrospect that in spite of other cardiovasoular and respiratory changes all cases were significantly embarrassed by the circulatory effects of their fistulae (our information is that all the shunts were $5 \mathrm{~mm}$. in size at the time of construction), and it was for this reason we closed the fistula in Case 3. It is interesting that a clinically small shunt may have created such haemodynamic effects, but we feel sure that this shunt was responsible for the patient's symptoms and cardiovascular state.

In the light of our experiences with these three patients we think it is important that such patients have adequate investigation, including measurement of cardiac output after exercise both with the shunt occluded and open.

We are interested in the sudden deaths described by Verberckmoes et al. (1967), and, as already mentioned, we know of one similar case. It is possible that Case 2 may be a further example, for, though he was ill from a combination of factors, the suddenness of his death was unexpected.

We wish to thank Professor R. Y. Calne for permission to publish details of patients under his care. We are grateful to the Cardiological Unit at Papworth Hospital for the cardiac output measurement in Case 3. We thank Dr, P. R. Millard for his help in the preparation of this paper.

\section{REFERENCES}

Ackman, C. F. D., Khonsari, H., Mount, B., Rege, P., and Dossetor, J. B. (1967). In Proceedings of the European Dialysis and Transplant Association, vol 4, D. 86 , edited by D. N. S. Kerr, D. Fries, plant Association, vol. 4, p. 86, edited Medica International Congress Series. No. 155. Amsterdam.

Anderson, D. C., Emslie-Smith, D., Macgregor, A. M. C., and Stewart, W. K. (1967). Brit. med. F., 2, 842.

Brescia, M. J., Cimino, J. E., Appel, K., and Hurwich, B. J. (1966). New Engl. F. Med., 275, 1089.

Calne, R. Y., et al. (1968). Brit. med. f., 2, 404

Hanson, J. S., Carmody, M., Keogh, B., and O'Dwyer, W. F. (1967). Brit. med. F., 4, 586 .

Klinkmann, H., Rohmann, H., Teichmann, G., and Müller, T. (1967). In Proceedings of the European Dialysis and Transplant Association, In Proceedings of the European Dilys, D. Fries, and R. Walter Elliott, Excerpta Medica International Congress Series, No. 155. Elliott, Excer

Patel, R., Lidsky, I., Vertes, V., Kest, L., and Cohen, S. (1968). Brit. med. \}., 1,414 .

Verberckmoes, R., et al. (1967). In Proceedings of the European Dialysis and Transplant Association, vol. 4, p. 73, edited by D. N. S. Kerr, D. Fries, and $\mathrm{R}$ Walter Elliott. Excerpta Medica International Congress Series, No. 155. Amsterdam.

\title{
Clinical Trial of 6\% Hydroxyethyl Starch* (a New Plasma Expander)
}

\author{
TORIOLA F. SOLANKE, $†$ M.B., CH.B., F.R.C.S.
}

\begin{abstract}
ummary : No adverse effects were seen in 29 patients given an intravenous infusion of $6 \%$ hydroxyethyl starch solution. Platelet counts had fallen by eight hours after infusion, but had reached pretransfusion levels by 24 hours. Two patients developed unusual bleeding postoperatively, which was possibly due to the infusion. Further investigations on the first stage of coagulation and prothrombin generation in patients receiving hydroxyethyl starch are required.
\end{abstract}

\section{Introduction}

For some time starch has been known to have a colloid effect when administered intravenously. However, ordinary starch solutions are physically unstable; moreover, rapid enzymatic

\footnotetext{
* $6 \%$ Hydroxyethyl starch in $0.9 \%$ sodium chloride was supplied by Don Baxter Co., Glendale, California, U.S.A.

t Department of Surgery, University College Hospital, Ibadan, Nigeria.
}

destruction occurs in the blood stream. In 1959 the use of physically stable branched or waxy polymers of starch and the introduction of hydroxyethylation to resist enzymatic hydrolysis initiated the re-examination of starch as a plasma expander.

The starting-point for hydroxyethyl starch synthesis is waxy sorghum starch, which is composed of over $95 \%$ amylopectin. Reaction with ethylene oxide introduced hydroxyethyl groups, which are attached by an ether linkage to the hydroxyl groups of the amylopectin. The number of hydroxyethyl groups attached to a molecule is reflected by a number called the degree of substitution, which is defined as the average number of hydroxyethyl groups per glucose residue. The hydroxyethyl starch used in this trial has a degree of substitution of 0.7 , which means it contained on the average seven hydroxyethyl groups per every 10 glucose residues.

The important properties of hydroxyethyl starch from the medical viewpoint are its molecular weight $(400,000-450,000)$ and the intravascular persistence of two weeks which depends 